
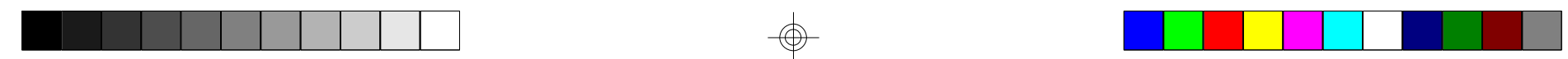

GEOUSP - Espaço e Tempo, São Paulo, No 18, pp. 237 - 243, 2005

\title{
TESES DE DOUTORADO E DISSERTAÇÕES DE MESTRADO DEFENDIDAS
}

\author{
(Maio de 2005 a Outubro de 2005)
}

\section{Teses de Doutorado}

\section{की}

Uso do território brasileiro e os serviços de saúde no período técnico-científico-informacional

Eliza Pinto de Almeida

Orientador: Prof. Dra. Maria Adélia A. de Souza

A Constituição de 1988 abriu um novo capítulo na história da saúde pública brasileira, quando pela primeira vez se reconhece a saúde como um direito do cidadão e um dever do Estado. Para que esse direito seja realmente exercido é necessário que cada cidadão possa usufruir plenamente dos serviços de saúde, independentemente do lugar que esteja ocupando no território brasileiro. A implantação do Sistema Único de Saúde, uma verticalidade institucional tem conduzido ao processo de descentralização dos serviços de saúde. Por intermédio de um conjunto normativo assistimos ao processo de habilitação dos estados e municípios para que esses tenham responsabilidades definidas segundo a modalidade de gestão a que estão habilitados. Os municípios são os protagonistas desse processo, daí o nosso interesse em conhecer mais detidamente a situação desses entes federativos. A ausência de dinamismo econômico de boa parte dos municípios brasileiros, fruto da seletividade do meio técnico-científicoinformacional, é um dos fatores que interferem no pleno funcionamento do SUS. Por intermédio do conceito de território usado buscamos desvendar as distintas situações geográficas que marcaram a organização dos serviços de saúde, especialmente no atual período histórico, marcado pelo aprofundamento do processo de globalização da economia

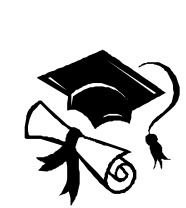

"Excluídos" : ex-moradores de rua como camponeses num assentamento do MST

\section{Marcelo Gomes Justo}

Orientador: Prof. Dr. Ariovaldo Umbelino de Olieira
Os objetos desta tese são os conflitos internos num assentamento de reforma agrária cuja luta foi organizada pelo Movimento dos Trabalhadores Rurais Sem Terra (MST) e a relação entre a trajetória de ex-moradores de rua da cidade de São Paulo e este movimento de luta pela terra. Foram tratadas duas hipóteses: primeira, a ida para o campo pode 
ser uma alternativa não-capitalista para o problema social dos moradores de rua; e, segunda, os assentados encontram formas de gerir de maneira pública os conflitos sociais referentes à vida em comum no assentamento. A investigação decorrente destas hipóteses propiciou compreender como se constitui a alternativa e quais são as limitações da gestão do assentamento. Ao longo da tese, comprovase que o trabalho do MST de conquistar um assentamento possibilita que os moradores de rua criem ondições de vida e de produção que Ihes dão indepedência em relação ao mercado de trabalho assalariado. Porém, verifica-se que para a realização de uma alternativa na área da economia solidária é preciso que os moradores de rua cheguem ao assentamento com maior força como grupo, que tenham alguma organização inicial e que estejam ligados a redes. Quanto à segunda hipótese, constata- se que os assentados tanto buscam formas judiciais quanto não-judiciais de gestão dos conflitos internos e que há o potencial de uma gestão pública do assentamento com relativa autonomia em relação ao Estado. No entanto, entre aos moradores o aprendizado de formas democráticas de gestão de conflito ainda é incipiente. Demonstra-se como os conflitos internos configuram o território, mapeando as redes de alianças e ataques entre os assentados. Neste sentido, contribui-se para os estudos geográficos sobre a fração de território camponês acrescentando a noção de redes como componente central da dinâmica da disputa de poder no assentamento. Problematiza-se a questão do ethos camponês como elemento de aptidão para a permanência como assentado. Mostra-se que o ethos é objeto de disputa entre os assentados, que reivindicam entre si maior legitimidade como camponês.

\section{exes ex}

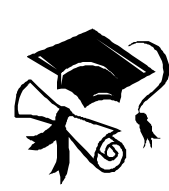

\section{A questão nacional na geografia ratzeliana e sua assimilação no pensamento social brasileiro na república velha}

João Phelipe Santiago

Orientador: Prof. Dr. Francisco Capuano Scarlato

Este trabalho trata da assimilação da geografia de Ratzel no contexto brasileiro na República Velha. para tanto, foram efetuadas análises dirigidas para o penamento social brasileiro. Utilizamos os métodos: histórico, analítico e dialético. Assim, partimos do contexto alemão, onde se engedrou o processo de desenvolvimento do capitalismo e da unificação nacional, culminando com o advento do Reich como potência mundial. Desse Zeitgeist, emerge a geogafia como ciência insitucional, tendo Friederich Ratzel como marco na produção de uma geografia positivista do Estado, na qual está refletida sua resposta á questão nacional. Este trabalho elucida os fundamentos do paradgma ratzeliano, discutindo as noções e as categorias essenciais de sua concepção de espaço geográfico numa perspectiva geopolítica nacional e mundial. Essa concepção ratzeliana constitui-se num referncial teórico essencial para correlação e confronto com as outras estruturas lógicas refletidas no rol bibliográfico investigado. De forma comparativa, delineamos a emergência da questão nacional no Brasil, momento em que o país atravessava uma grande mudançana sua configuração geográfica, deixando de ser escravista através do desenvolvimento das relações capitalistas e se destacando na expansão da cafeicultura no Sudeste e a crescente urbanização, que levaram - Estado de São Paulo a se tornar economicamente o mais poderoso de toda Federação. Paralelamente, revelamos comos os modelos científicos, associados às interpretações da sociedade, foram assimilados 

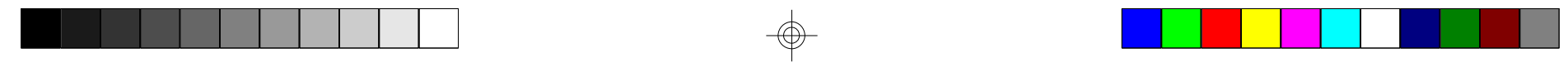

Teses de Doutorado e Dissertações de Mestrado Defendidas

(Maio de 2005 a Outubro de 2005), pp. 237 - 243

pela intelectualidade brasileira, e equacionamos as razões da recepção e da adoção de idéias de Ratzel no contexto da Reública Velha. Finalizando, analisamos propriamente a assimilação do pensamento de Ratzel no Brasil, reconstruindo um temário sobre a questão nacional, em conexão com o debate existente nas obras dos autores Alberto Torres, Elysio de Carvalho, Oliveira Vianna e Everaldo Backheuser. tentamos destacar a importância deste estudo para a atualidade.

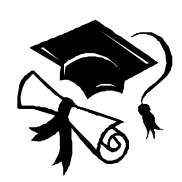

O financiamento e a financeirização do setor imobiliário: uma análise da produção do espaço e da segregação sócio-espacial através do estudo do mercado da moradia na cidade de Sâo Paulo

\section{Adriano Botelho}

Orientador: Profa. Dra. Margarida Maria de Andrade

O presente trabalho tem como tema o estudo do processo de produção e consumo do espaço que ocorre no modo de produção capitalista contemporâneo, focalizando a união entre o setor imobiliário e o capital financeiro em suas relações com o processo de urbanização. O objetivo da pesquisa foi o de analisar como a crescente integração do capital financeiro com o setor imobiliário tem por conseqüência uma maior fragmentação do espaço e um aprofundamento da segregação sócio-espacial em São Paulo. A hipótese levantada foi a de que o desenvolvimento dessa integração aumentaria o poder do capital monopolista sobre as melhores localizações na cidade, intensificando a fragmentação do espaço urbano, consolidando a sua hierarquização e o processo de segregação sócio-espacial na cidade.Para a viabilização dessa pesquisa, privilegiou-se o estudo da produção da moradia na cidade de São Paulo em suas articulações com o setor financeiro, num contexto de transformações das formas de financiamento habitacional em âmbito nacional a partir da década de 1990. Dessa forma, foram analisados três casos de empreendimentos imobiliários na cidade de São Paulo: Fundos de Investimentos Imobiliários [FII's] e Certificados de Recebíveis Imobiliários [CRI's], através do FII Panamby; cooperativas habitacionais (autofinanciamento), com o caso da Paulicoop Planejamento e Assessoria; e provisão estatal de moradia através de Companhias Habitacionais, com a análise do caso do mutirão City Jaraguá sob responsabilidade da CohabSP. O estudo de cada caso, destacando-se a sua localização no urbano e as características do mercado a que se destina, revelou importantes elementos do processo de hierarquização, fragmentação e segregação no espaço da metrópole paulistana. 

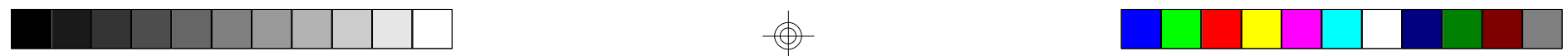

\section{Dissertações de Mestrado}

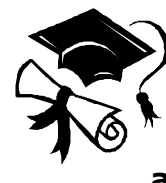

Infra-estruturas em energia e transportes e crescimento econômico na China : o enfrentamento da crise financeira asiática a partir da expansão de sua demanda interna e a formação de uma economia continental

Elias Marco Khalil Jabbour

Orientador: Prof. Dr. Armen Mamigonian

A crise financeira que assolou a Ásia no ano de 1997 demonstrou que a China possuía, igualmente seus vizinhos asiáticos, problemas em sua estrutura econômica e financeira. Os chineses reagiram a esta crise implementando uma política que contemplasse a expansão de sua demanda doméstica e a formação nas próximas décadas de uma economia continental que consolidasse o poder estatal sob o território e a sociedade do país. As condições objetivas para esse enfrentamento foram criadas ao longo de 20 anos de política de Reforma e Abertura: capacidade produtiva, sistema de intermediação financeira e o efetivo controle do Estado Nacional em todos os terrenos da governança chinesa. O verificado alavancamento dos investimentos nas infra-estruturas em energia e transportes constitui, assim, meio para abrir um novo ciclo de desenvolvimento econômico com expansão considerável de sua demanda doméstica e ao mesmo tempo viabilizar a formação de uma economia continental com impactos no mundo semelhantes aos verificados no momento em que os Estados Unidos da América consolidaram seu atual território na segunda metade do século XIX

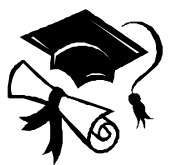

Fronteira Brasil-Colômbia: formação, vigilância e vivificação

Luiz Alves Brígido Maia

Orientador: Prof. Dr. André Roberto Martin

Este trabalho consiste em fazer um levantamento da formação das fronteiras brasileiras na região amazônica, enfocando o trecho com a Colômbia. Destaca a formação da fronteira e a faixa de fronteira, onde o Estado Brasileiro tem uma atuação mais direta, desenvolvendo projetos e políticas territoriais. A importância da presença militar na vigilância e vivificação da área, sobretudo o Exército Brasileiro com seus Batalhões e Companhias de Fronteira, também será destacada. A espacialização de suas unidades e aumento do efetivo militar nos últimos vinte anos demonstra a importância desta fronteira e os interesses de diferentes atores sociais na região.0 narcotráfico, a evasão de divisas, o contrabando, a biopirataria, FARC, ou mesmo a presença militar dos EUA com seus soldados auxiliando a Colômbia no combate ao narcotráfico, nos mostra que do lado colombiano os problemas são muitos. Assim, devemos ficar atentos para que estes problemas não atinjam nossa soberania e os interesses nacionais na fronteira Brasil-Colômbia 


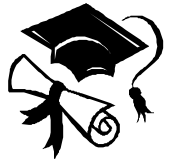

Assentamento rural : conflitos internos e a territorialização do MST - um estudo de caso

\author{
Raildo Silva de Alencar
}

Orientador: Prof. Dra. Marta Inez Medeiros Marques

A espacialização do Movimento dos Trabalhadores Rurais Sem Terra e sua territorialização é um processo dinâmico, determinado pela exclusão sócio-econômica pela qual passa grande parcela da população do país. Essa parcela excluída busca, por intermédio do movimento social, sua re-inserção na sociedade através da conquista da terra, vista como objeto e meio para o resgate da vida. Esses excluídos constituem uma heterogeneidade nos espaços de socialização dos assentamentos, engendrados pelo movimento social e, embora originados dos mesmos fatores de exclusão, refletem realidades territoriais e culturais variadas. A mescla de origens de vida distintas desenvolve uma socialização rica no processo, que apresenta dificuldades, mas também possibilidades de socialização. As concepções desenvolvidas neste trabalho são apresentadas a partir de um estudo de caso: o assentamento Nova Esperança 1, em São José dos Campos. Desta forma, algumas idéias devem ser relativizadas e circunscritas à área de estudo. Fatores locais influenciam no processo de territorialização do MST e dos assentados, tais como: o desejo pelo reconhecimento, a importância do vínculo familiar, as noções de liberdade, além da influência da organização sócio-econômica capitalista. Esses fatores desenvolvem conflitos sociativos que marcam a construção permanente do movimento social, de suas estratégias e a compreensão dos trabalhadores do processo político
Telemática no ensino de geografia : uso da web como ferramenta interdisciplinar e de percepção ambiental de estudantes do ensino supletivo do município de Cubatão

\section{Felizardo Delgado}

Orientador: Prof. Dr. Reinaldo P. Machado

Este trabalho tem por objetivo investigar as possíveis contribuições do uso da telemática e hipertexto no trato das questões ambientais no ensino formal oferecendo subsídios para o desenvolvimento da educação ambiental, através de um levantamento das percepções dos estudantes a respeito dos problemas ambientais na realidade social em que estão inseridos, bem como em relação à saúde, pobreza, entre outros. Iniciou-se verificando se houve melhoria da percepção da problemática ambiental, com a introdução de recursos áudiovisuais como a telemática e hipertexto no processo de ensino-aprendizagem, utilizando a sala de informática da Escola Municipal de Ensino Fundamental e Supletivo 'Padre José de Anchieta", situada no município de Cubatão Estado de São Paulo, onde existe um projeto social da Carbocloro S.A. - Indústrias Químicas, que patrocina o projeto "Cidade do Amanhã" (www.cidadedoamanha.g12.br). A pesquisa foi realizada entre o segundo semestre de 2003 e o primeiro semestre de 2004 num universo de investigação constituído por alunos de 7a e 8a séries do ensino supletivo. A metodologia empregada partiu-se de uma análise qualiquantitativa realizada a partir de uma amostra aleatória, constituída por $30 \%$ de um universo de 200 alunos. A análise é procedente da experiência adquirida depois de atuar durante cerca de dois anos no projeto Cidade do Amanhã, das aulas de introdução à informática, do 
convívio e interação com os discentes, da navegação em sites ligados ao meio ambiente e de comentários recebidos dos professores e alunos. Procura-se estimular a continuidade do projeto de educação ambiental através da telemática e hipertexto, apesar das dificuldades de implementação no currículo e ambiente escolar, notadamente no curso noturno e ao nível da educação de jovens e adultos

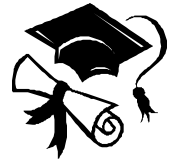

\section{Espaços livres públicos : um estudo no município de Ilhabella (SP)}

\section{Andréa Presotto}

Orientadores: Prof. Dr. José Bueno Conti e Prof. Dr. Felisberto Cavalheiro (in memorian)

Devido às dificuldades que os municípios enfrentam para solucionar os problemas de suas áreas mais urbanizadas, um planejamento, que fosse capaz de manter espaços livres, poderia contribuir para a população que escolheu a vida nas cidades como alternativa, proporcionando ao homem soluções que auxiliem na melhoria das condições de vida e na manutenção de uma paisagem apropriada. Esta pesquisa preocupouse em identificar apenas um problema em relação a tantos outros que existem: os espaços livres públicos inseridos na paisagem urbana e a falta de planejamento para que os espaços que quebram a continuidade dos espaços construídos sejam mantidos livres. Sabe-se que os espaços livres têm funções nobres nas cidades: melhorar as condições ambientais, contribuir para o planejamento da paisagem e estética, proporcionar oportunidades de lazer para a população, entre outras. Foi realizado um levantamento de bibliografia específica e para analisar como os espaços livres públicos vêm sendo planejados e tratados no Brasil, o município de Ilhabela (SP), sediado na Ilha de
São Sebastião, foi escolhido por apresentar as condições necessárias para o desenvolvimento desta pesquisa. Grande parte dos residentes do município localiza-se em áreas desprovidas de espaços livres, onde a consideração objetiva da paisagem foi negligenciada em favor das soluções das necessidades de moradia. Contudo, os moradores demonstram suas necessidades transformando a paisagem e construindo seus próprios espaços livres para lazer. Conceitos de paisagem e de espaços livres públicos foram profundamente analisados ao se organizar as bases teóricas desta pesquisa. Os objetivos da pesquisa voltaram-se para as necessidades que os moradores no município de Ilhabela, nas proximidades do Parque Estadual de Ilhabela, têm de espaços livres públicos para suas atividades de lazer, discutindo-se também alguns conceitos sobre as características de espaços livres públicos úteis aos moradores e ao ambiente. Foram levantados os espaços livres com bases nos conceitos adotados em três bairros em Ilhabela: Água Branca, Reino e Greenpark. Para conhecer os anseios da população em relação as possibilidades de melhorias dos bairro onde vivem, foi aplicado um questionário $(n=100)$ e seus resultados foram analisados com apoio de programas estatísticos. Conclui-se que existe a necessidade de implantação de espaços livres públicos que possam atender a população dos bairros, porém os entrevistados, não sentem necessidade de grandes mudanças, apenas desejam a organização dos bairros, para suprir seus desejos.

$$
\text { eseses }
$$




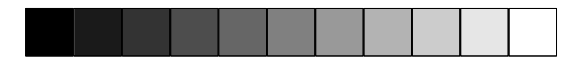

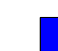

Teses de Doutorado e Dissertações de Mestrado Defendidas

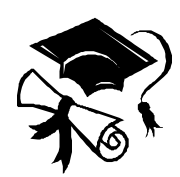

\begin{abstract}
Representações gráficas do relevo e álgebra de mapas : aplicações no estudo da fragilidade ambiental
\end{abstract}

Fernando Shinji Kawakubo

Orientador: Prof. Dr. Ailton Luchiari

Este trabalho tem como objetivo realizar - mapeamento da fragilidade ambiental utilizando técnicas de Geoprocessamento. Uma ênfase é dada aos procedimentos que envolvem a Modelagem Digital do Terreno (MDT) e as técnicas de integração de mapas denominadas de Álgebra de Mapas - mais especificamente
Álgebra de Campo. Duas metodologias empíricas de fragilidade ambiental foram utilizadas. A primeira se baseia na metodologia proposta por Ross (1994) e a segunda, nas Unidades Territoriais Básicas (UTBs) sistematizada por Crepani et al. (1996). As técnicas de Geoprocessamento empregadas neste trabalho mostraram a importância dos sistemas computacionais na elaboração de mapas intermediários e de síntese. Em relação aos mapas sínteses que expressam a fragilidade do ambiente, os mapas produzidos a partir da metodologia de Ross (1994) apresentam maior grau de fragilidade que os de Crepani et. al (1996). Estas diferenças devem-se principalmente a forma como os mapas analíticos foram combinados

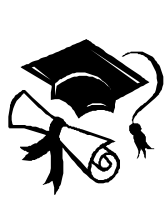

Fragilidade pontencial do relevo : estudo geomorfológico da bacia hidrográfica do Ribeirão da Mococa - Cristais Paulista, São Paulo

Fernando Nadal Junqueira Villela

Orientador: Prof. Dr. Jurandyr L. Sanchez Ross

Este estudo propõe-se a cartografar bacia de drenagem localizada no nordeste do Estado de São Paulo, no município de Cristais Paulista. Para tal, faz uso dos meios atribuídos à Geografia Física, através de um estudo eminentemente cartográfico, fotointerpretativo, informacional e bibliográfico, visando a compreensão geomorfológica do espaço escolhido, a Bacia Hidrográfica do Ribeirão da Mococa. O principal apoio teórico-metodológico, obtido através da Geomorfologia, adota como parâmetros básicos as abordagens de TRICART (1965 e 1977), TRICART \& KILIAN (1982) e as proposições de ROSS (1991, 1992 e 1994), resultando em cartografia detalhada através da utilização de Sistemas de Informação Geográfica (SIG). Em razão do meio físico não se restringir a divisões das ciências, ocorre também certa aproximação com outros ramos de conhecimento, como a Geologia, Pedologia, Climatologia e Hidrologia. Baseado na hierarquia taxonômica e na funcionalidade dos atributos da paisagem, o principal enfoque é a definição de unidades de paisagem, que representem a fragilidade natural potencial da área de estudo aos processos morfodinâmicos, através da combinação de atributos do relevo (modelado, morfometria, morfogênese, entre outros) que forneçam informações qualitativas do meio natural 
